\title{
Designing of Three Level 3 Phase Inverter Using Improved SPWM Modulation for different Loads
}

\author{
AnshuSharma $^{a}$, Ashish Singhal ${ }^{b}$ \\ ${ }^{a}$ M. Tech Scholar \\ ${ }^{\mathbf{a}, \mathbf{b}}$ Sagar Institute Science, Technology and Engineering, Bhopal \\ infoanshu@gmail.com, ${ }^{\mathrm{b}}$ ashishee@gmail.com
}

Article History: Received: 10 November 2020; Revised 12 January 2021 Accepted: 27 January 2021; Published online: 5 April 2021

\begin{abstract}
Many high voltage applications require three-phase inverters. The major challenge in inverter designing is the mitigation of harmonic distortion (HD) to achieve better inverting performance. Usually, sinusoidal pulse width modulation (SPWM) is widely used to trigger the inverting switches for controlling the total HD performance in the inverter. To provide the option of multiple operating ranges the multilevel inverters are designed for higher voltage operations. This paper contributes in two passes, first, an improved SPWM modulation is generated for designing the three levels inverter. Then in the second pass, the performance of the THD is evaluated under the different load conditions using V-I measurement. THD is present in the system due to the use of switches. Therefore, this paper has evaluated the performance of the proposed improved SPWM based multilevel inverter for analysis. In order to improve the performance, the modulation index of the SPWM block is varied. The performance of the component report is also presented in the short..the output waveform of the line current and the voltage are compared; The FFT analysis is done to evaluate the comparison of THD performance. It is concluded that improving the SPWM performance and the lording conditions may improve the THD performance also.
\end{abstract}

Keywords: Three Phase Inverter, Three-level Inverter, FFT Analysis, THD, SPWM, Modulation Index

\section{Introduction}

With the invention of the fast switching characteristic of the different electrical inverting switches, the harmonic performance of inverters has become a great challenge during the last decades. Many Inverting challenges have been proposed by the researchers [1,2 and,3]. Therefore it is highly desired to minimize the total harmonic distortion (THD) performance of the high voltage Inverters.

The task of the inverting action is to produce the AC voltage from the input battery-operated DC Power source. The process of inverting operation is shown in Figure 1.

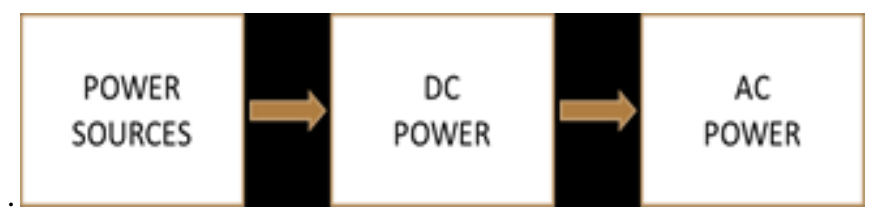

Figure 1.Process of the Inverting Operation

Many high voltage industrial applications are required to use multilevel inverters (MLI). Thus improving the performance of designed MLI is require to improve the utilization for industrial uses,

As there are various types of inverters available in the literature thus in the beginning the classification of the inverter design is presented in Figure 1. The broadly inverting operation is classified as single-phase and threephase. Then our main concern is to focus on cascaded $\mathrm{H}$ bridge inverters. The inverters are classified base on the level of trace used in multilevel inverters. In this paper, our prime concern will be to compare the performance of each of these inverters based on the THD and FFT analysis. It is highly desired to minimize the THD in inverter designs. 


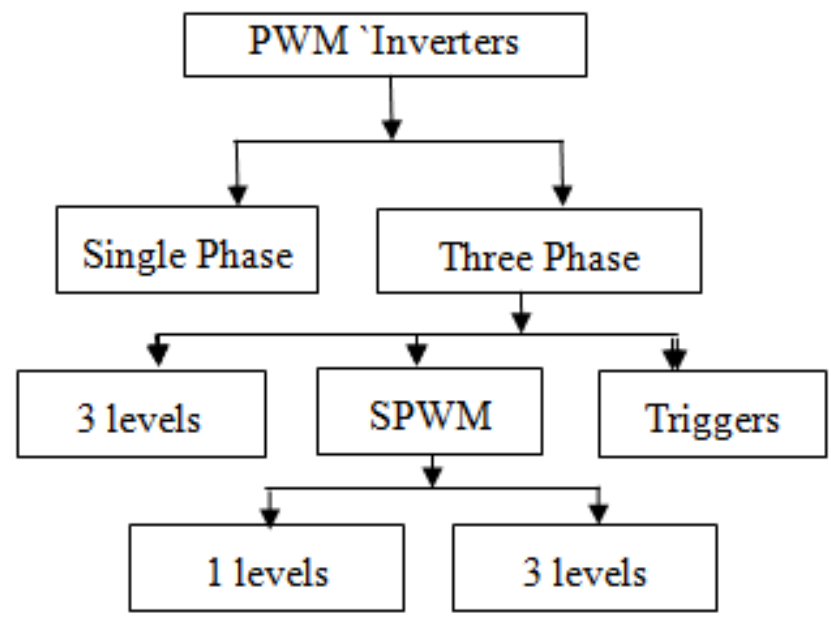

Figure 1 Classification of Multilevel PWM inverters.

The basic structure of SPWM based inverting pulse generation is shown in Figure 3. It can be observed that by varying the parameters of the sine waves and the trigger pulses the output pulses can be controlled. Thus using SPWM may improve the performance of the conventional multi-level inverters. .comparator is used for gemmating the error signal for deciding transition.

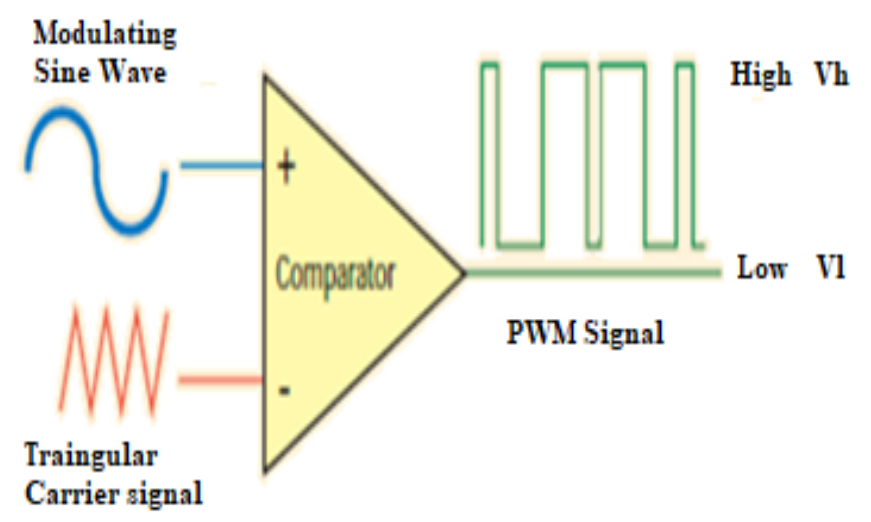

Figure 3 The operation of triangular pulses to based SPWM process

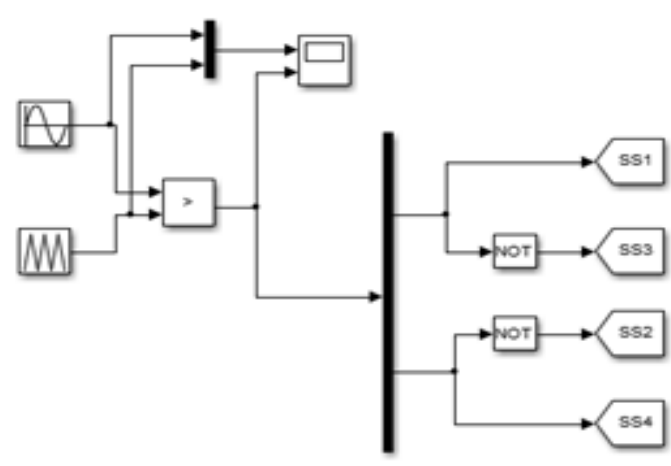

Phase a

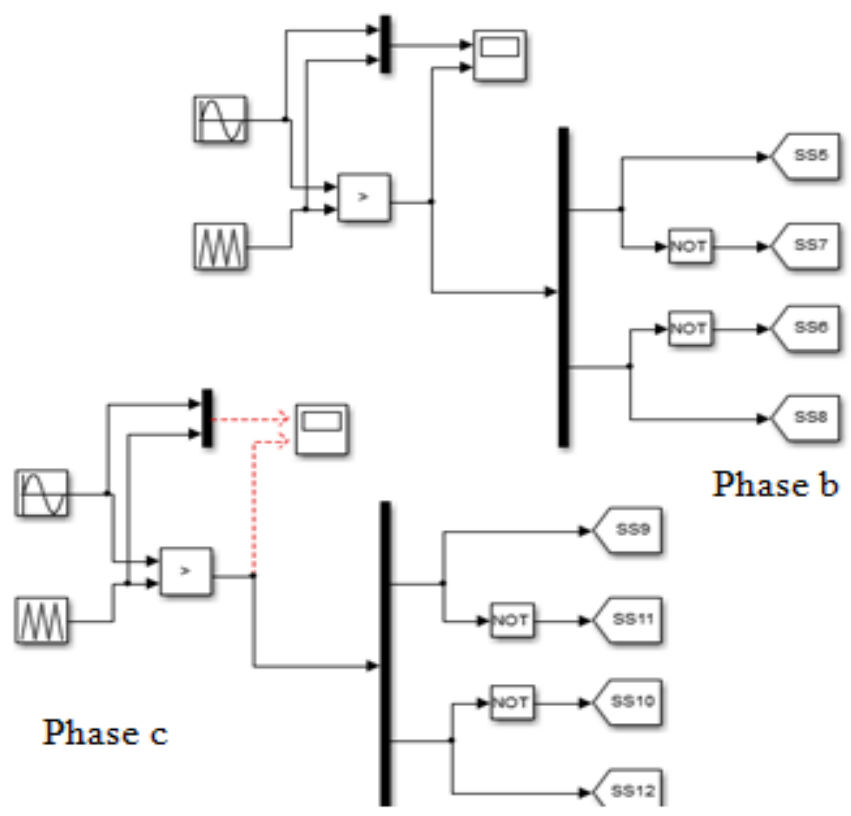

Figure 4 SPWM Blokes used for triggering the A, B C three-phase cycles of the voltage switches. 
The basic model structure for the generation of the SPWM trigger for the switching operations is shown in Figure 4 and the corresponding output pulses are given in Figure 5. It can be observed from the Figure that the PWM pulses are produced for switching using SPWM input.

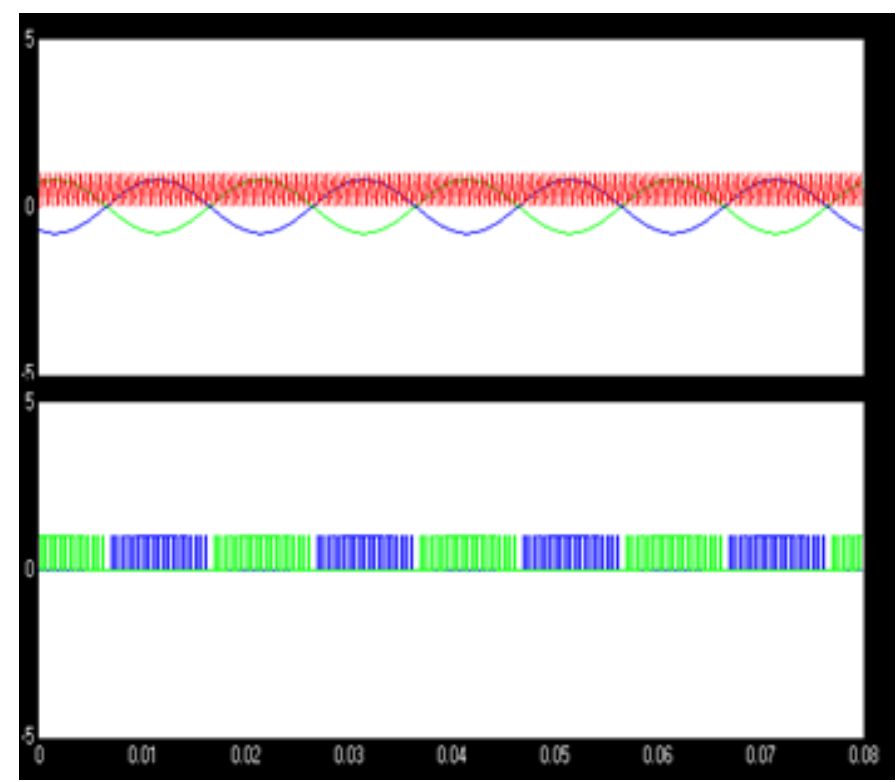

Figure 5.The switching waveforms of the single-phase SPWM system used here.

\section{Why MLI Designs}

There are many applications of the MLI designs the basic advantages of using the MLI design are as follows.

Benefits of Using MLI.

- It provides the higher power using medium sources

- $\quad$ MLI operated through using the number of switches

- $\quad$ May reduce very Low Distortion

- $\quad$ Reduce the dv/dt stresses

Common-mode voltage: (MLI) Multilevel may produce a lesser CM voltage range.

\section{Applications}

Major applications of MLI inverters are there the major applications are shown in Figure 6.

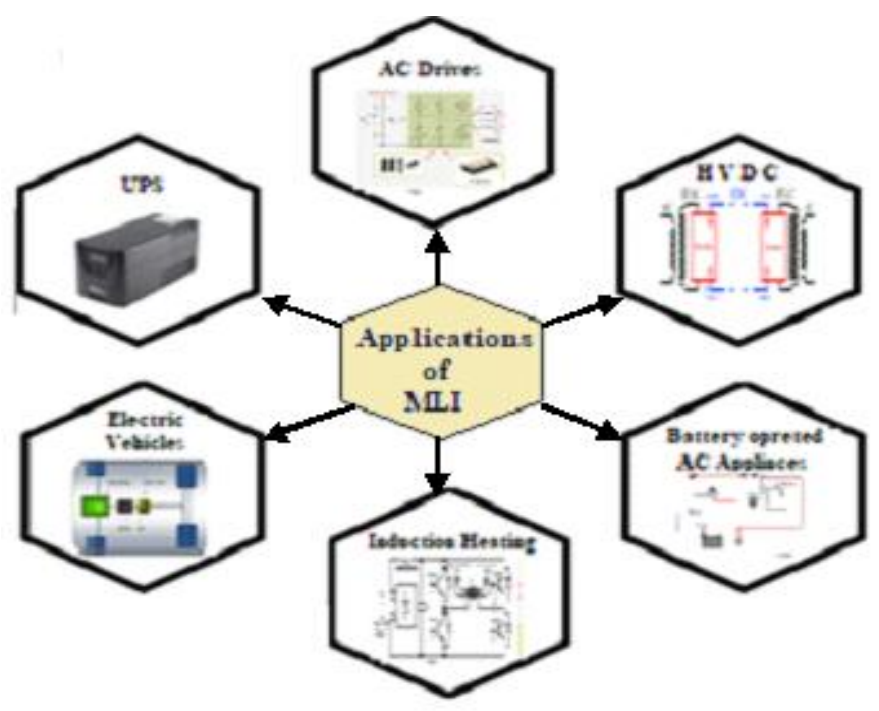

Figure 6 Applications of Cascaded $\mathrm{H}$ bridge inverters 
Mostly the ML inverters are used in the Hugh voltage drives-based applications. HVDC and electric vehicle are another heavy load applications

\section{Review of Multilevel Inverters}

The operation efficiency of the inverting operation depends on the performance of switches used for designing. Many architectures of cascaded $\mathrm{H}$ bridge $(\mathrm{CHB})$ inverters were designed to improve the performance. A. Ali et al [1] have used pulse width modulation (PWM)for improving the performance of the multi-level CHB inverters.

Table.1 Summary of Survey

\begin{tabular}{|r|l|l|l|}
\hline S. No. & \multicolumn{1}{|c|}{ Authors } & \multicolumn{1}{|c|}{ Type of Inverter } & \multicolumn{1}{|c|}{ Work } \\
\hline 1. & A. Ali et al [1] & $\begin{array}{l}\text { Multi-level CHB } \\
\text { inverters }\end{array}$ & $\begin{array}{l}\text { Used PWM for improving the performance of } \\
\text { the multi-level CHB inverters }\end{array}$ \\
\hline 2. & Anubha Gupta et al]2\} $&{\text { Three-phase inverter }} &{\begin{array}{l}\text { Have designed the three-pahse inverter using } \\
\text { the SPWM technique }\end{array}} \\
{\hline 3 .} &{\begin{array}{l}\text { Anuja Namboodiri et. al. } \\
{[4]}\end{array}} &{\begin{array}{l}\text { Three-phase SPWM } \\
\text { inverter }\end{array}} &{\begin{array}{l}\text { Design using SPWM analysis and reported } \\
\text { THD of 96\%. }\end{array}} \\
{\hline 4 .} &{\begin{array}{l}\text { Avinash Bajpayee et al } \\
{[6]}\end{array}} &{\begin{array}{l}3 \text { phase SPWM Bi- } \\
\text { polar inverter }\end{array}} &{\begin{array}{l}\text { Designed Bi polar inverters by controlling } \\
\text { triangular trigger pulse have achieved THD of } \\
88 \% .\end{array}} \\
{\hline 5 .} &{\begin{array}{l}\text { A. Palanisamy et al [11] } \\
6 .\end{array}} &{\begin{array}{l}\text { Three-phase three } \\
\text { level inverter }\end{array}} &{\begin{array}{l}\text { Designed the PW based new inverter for the } \\
\text { solar PV application }\end{array}} \\
{\hline}$
\end{tabular}

Anubha Gupta et al [2] have designed the 2 phase inverter based on the SPWM approach and presented a good comparison of the line and phase waveforms. The PWM is used for controlling the performance of switching. Anuja Namboodiri et. al. [4] have designed an inverter using SPWM analysis and reported the FFT analysis of the THD achieved to 96\%. E. Lee, et al [2] have opted for the modified PWM8 approach with phase-shifting to improve CHB inverting performance. The PWM is used for controlling the performance of cascaded $\mathrm{H}$ bridge inverter

Avinash Bajpayee et al [6] have improved the triangular trigger pulse for the SPWM switching and reported improvement of THD up to 88\%. A. Palanisamy et al [11] have presented the good application of the PWM based inverter for the solar PV cell s. of THD for various multi-level CHB inverters and concluded $23.54 \%$ for 9 level and $10.84 \%$ THD for 11 level CHB inverters L. K. Gupta et al [6] have presented the design of CHB inverter and presented minimum voltage THD of $28.9 \%$ for single-phase 4 level inverter.

\section{A 3 Level MLI Proposed Inverter}

There are various architectures designed for multilevel inverters the proposed three-level three-phase multilevel inverter is shown in Figure 6. Switch inversion operation is used for phase conversion. The proposed design is used for model creation in the final phase.

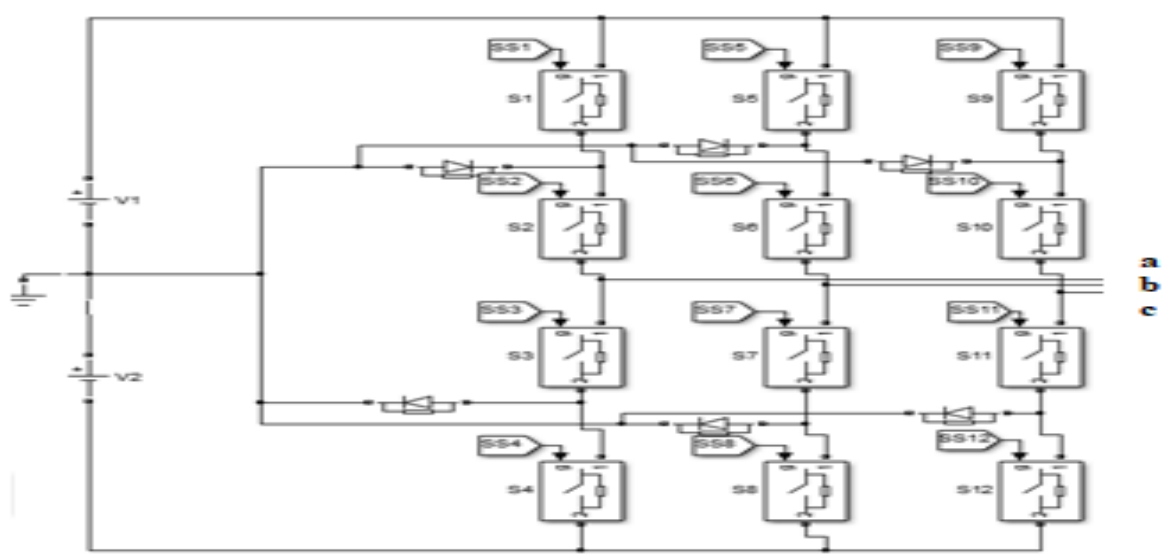


Figure 6 Design of the MLI inverter using

It can be observed that corresponding to each phase (amb,c) the colorsvise switched are named as S1a, to S4a, $\mathrm{S} 1 \mathrm{~b}$ to S4b, and S3c to S6C respectively. It can be observed that during the positive cycle switch S1 and S3 are on and during the negative cycle of the sine wave the switches are inverted to S2 and S4 will be Turn on. The 12 switches are used in this proposed design. In this work, it is proposed to change the modulation index and frequency of the PWM signal for evaluating the THD performance of the system. Besides, the duty cycle of the triangular wave can be used to change the trigger of the comperator block thus controls the switching of the waveforms. The proposed inverter design implemented the diodes in parallel with basic RC snubber circuits as shown in Figure 6. In on-state, the Diode model has an internal resistance (Ron) and inductance (Lon).

Besides, the Resistive and inductive loads are used for performance evaluation. the VL measurement block is used for analysis. Paper compared the FFT-based THD analysis of the different load conditions which may consider as the filter.

\section{Evaluations Of Multilevel Inverter}

Different simulation parameters consider for the modified inverter design are shown in Table 2. The approach of design is to modify the PWM design parameters for evaluating the THD performance.. the THD analysis is done for voltage and current both waves also it may be advantageous to improve the trigger triangular pulse sample times to improve the performance.

Table2 various design parameters.

\begin{tabular}{|c|c|c|}
\hline S. No. & Parameter & Values \\
\hline 1. & Modulation & SPWM \\
\hline 2 & Modulation index & 0.2 \\
\hline 3 & Reference Frequency & $50 \mathrm{~Hz}$ \\
\hline 4 & Modulation Frequency & $15 \mathrm{~Hz}$ \\
\hline 5. & $\begin{array}{c}\text { Switch internal } \\
\text { resistance }\end{array}$ & Rin $=0.001 \mathrm{ohm}$ \\
\hline 6 & Snuber resistance & $1 \mathrm{e} 5 \mathrm{ohm}$ \\
\hline
\end{tabular}

The section presents a performance evaluation of the various THD values achieved by the different CHB inverters. The waveform of the line voltage for the five-level cascade inverters is shown in Figure 8 . It can be observed the there are three levels of the waveform and each voltage phase has a 120-degree phase difference between them.

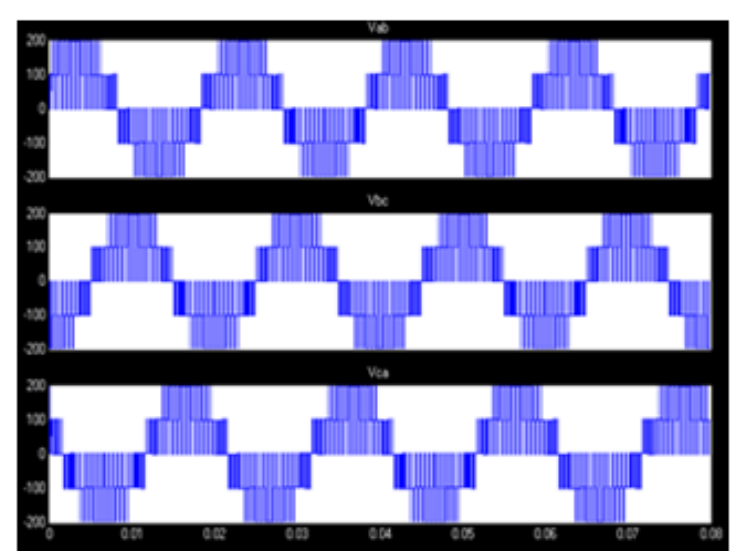

a) The phase voltage waveform.

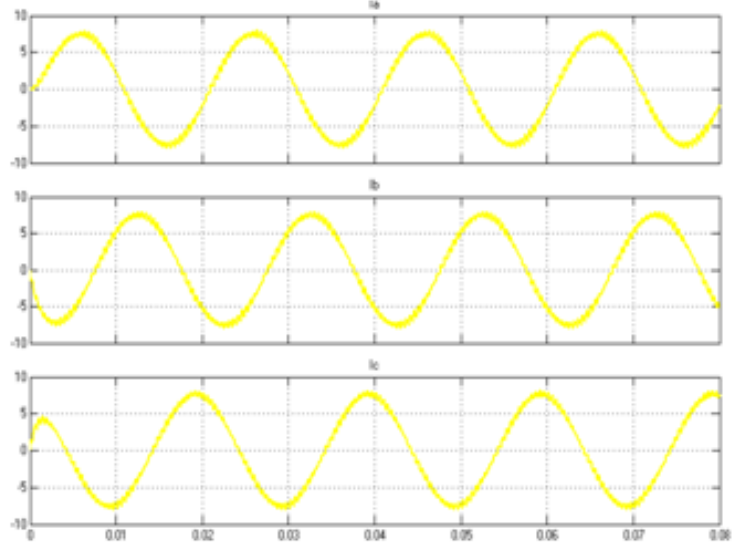

B) Current waveform of phase lines 
Figure 9 Output waveforms of proposed 3 level inverter

Table 3 Comparison of TSD for existing inverters and proposed methodologies.

\begin{tabular}{|c|c|c|c|}
\hline S No. & $\begin{array}{l}\text { Single Phase Inverter } \\
\text { [1] }\end{array}$ & Three phases inverter [4] & Proposed 3 level MLI \\
\hline 1. & $90.16 \%$ & 87.37 & $61.2 \%$ \\
\hline 2. & \multicolumn{2}{|c|}{ With Modified proposed SPWM } & $60.05 \$$ \\
\hline
\end{tabular}

\section{Parametric Comparison}

Total Harmonic Distortion (THD) is defined degree of closeness of the shape between output and its fundamental FFT component and is mathematically given as;

(1)

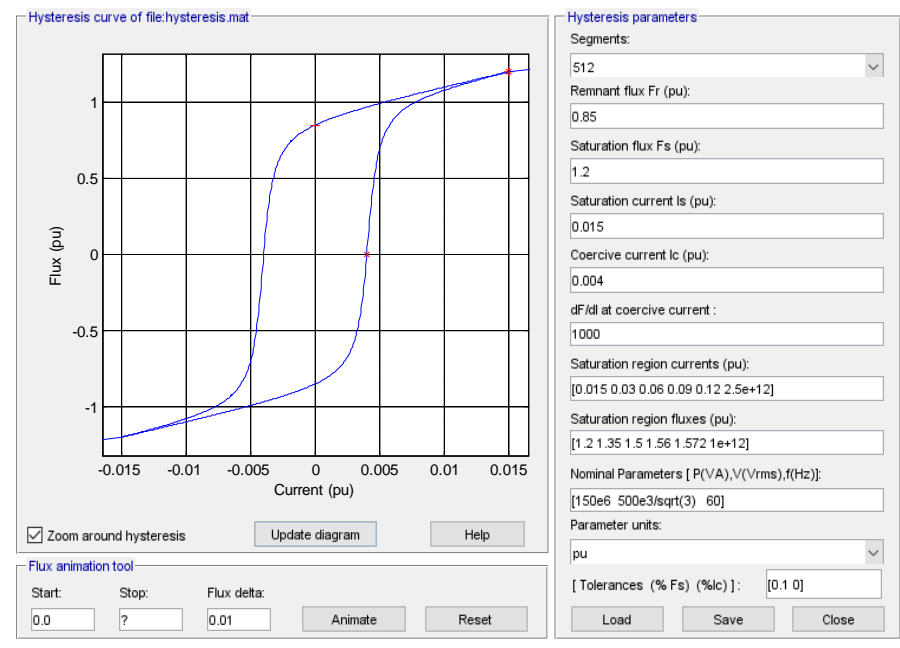

Figure 9 the hysteresis curve analysis if the Inverter circuit

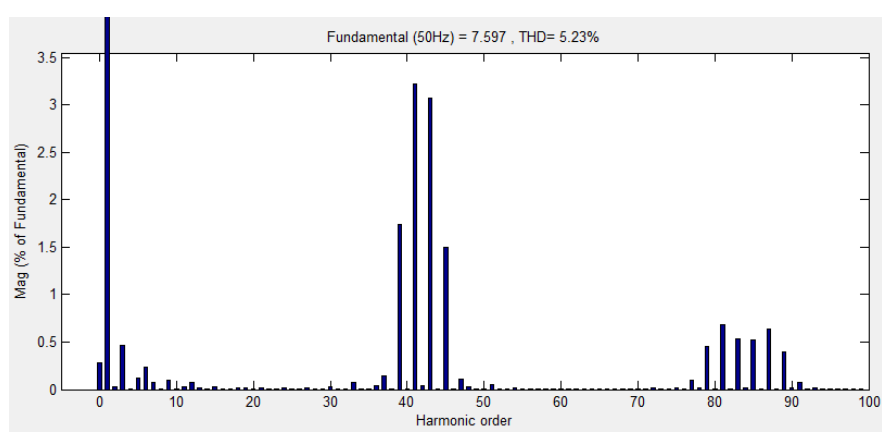

Figure 10 Current FFT analysis for THD for proposed design with RL load

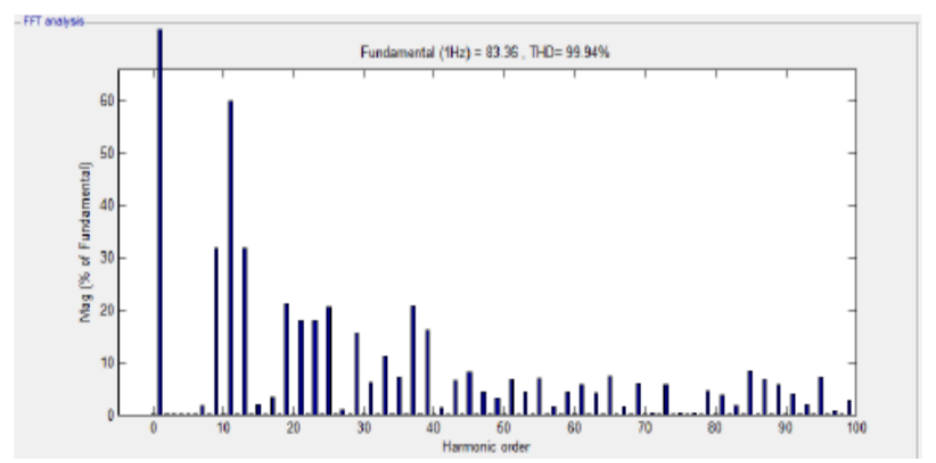

a) Anuja et al. [3] 


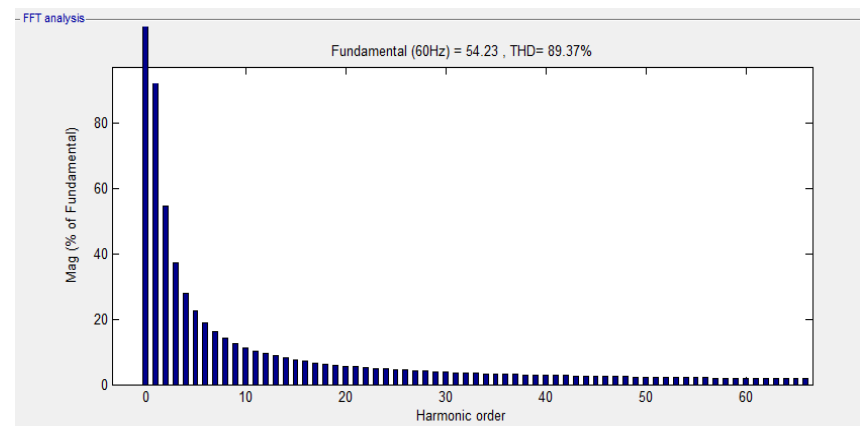

b) Avinash et al. [4]

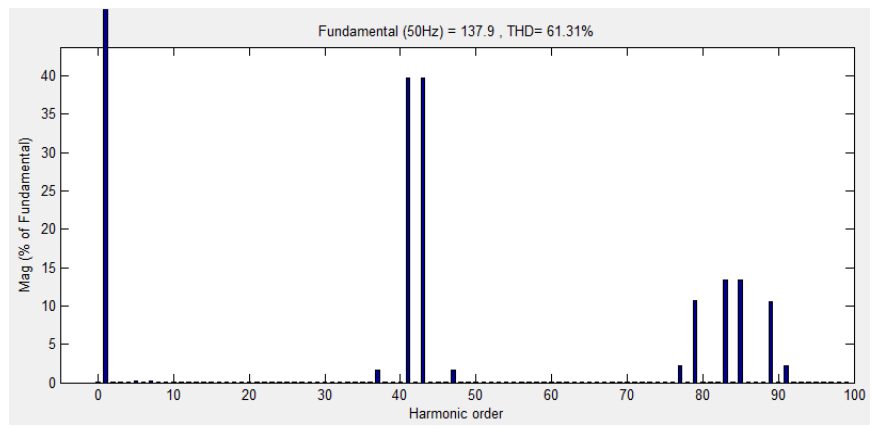

Figure 11 Voltage FFT analysis of the three-phase inverter THD comparison

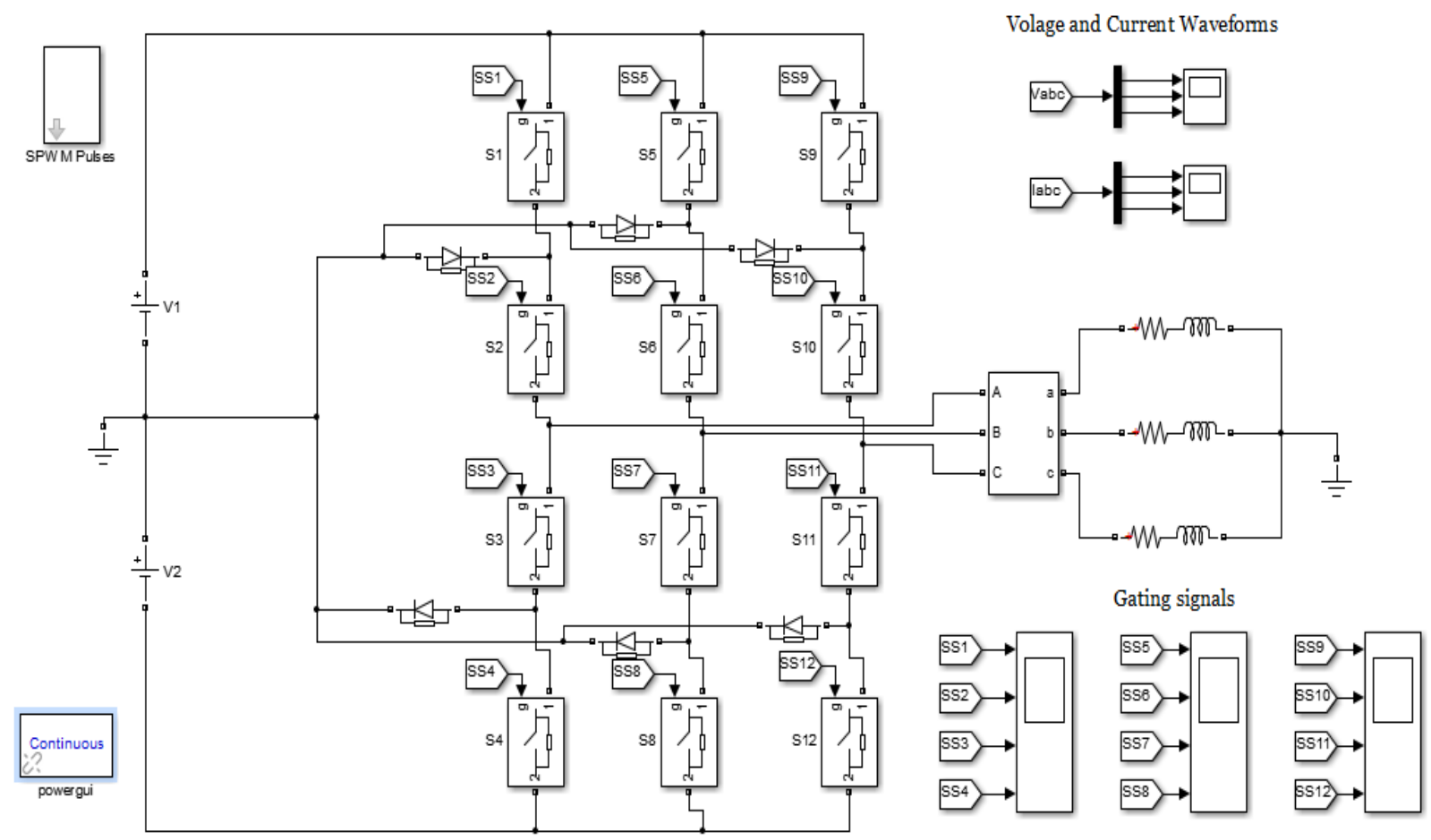

Figure 12: proposed 3 phase modified SPWM based three-level inverter designed

\section{Conclusions}

This paper proposed to design the modified SPWM based approach for improving the THD performance of the three levels 3 phase inverter. The reduction in harmonic distortion is a challenge in inverter design. It is required to achieve a good approximation of the sinusoidal nature of voltage output. The major focus of the paper is to evaluate the current and voltage waveform for THD using the FFT analysis by powergui block. The model is designed in MATLAB using Simulink. The proposed approach varied the modulation index of the SPWM wave for improving the performance. 
It is found that it is required to analyze the FFT performance for evaluating harmonic distortions. It is concluded that reduction in modulation index and frequency combination of SPWM may improve the performances of THD. It is concluded that THD performance is minimized by the proposed work. The RL snubber performs well enough.

It is also recorded to work to further reduce distortion in the current wave and the significant improvement may report in the future.

\section{Acknowledgment}

Authors heartily acknowledge everyone who has supported the current research. The authors also highly acknowledge all referenced authors for indirect contributions to the current research.

\section{References}

A. Ali and J. Nakka, "Improved performance of cascaded multilevel inverter," 2016 International Conference on Microelectronics, Computing and Communications (MicroCom), Durgapur, India, pp. 1-5 2016,

Anubha Gupta- “Three Phase Inverter Simulation using Sinusoidal PWM Technique “,J International Journal OF Advanced Research IN Electrical, Electronics AND Instrumentation Engineering Vol. 6, Issue 5, May 2017

Anuja Namboodiri , Harshal S. Wani, "Unipolar and Bipolar PWM inverters", IJIRST -International Journal for Innovative Research in Science \& Technology Volume 1| Issue 7 | December 2014

A. Singh and R. N. Mahanty, "Simulation of simplified SVM technique for three phase five-level cascaded Hbridge inverter," 2017 International Conference on Information, Communication, Instrumentation and Control (ICICIC), Indore, India, pp. 1-6, 2017,

E. Lee, S. Kim and K. Lee, "Modified Phase-Shifted PWM Scheme for Reliability Improvement in Cascaded HBridge Multilevel Inverters," in IEEE Access, vol. 8, pp. 78130-78139, 2020,

Avinash Bajpayee, Nilesh Diwakar, Mithlesh Gautam, Meha Shrivastava, "Analysis of the FFT Performance of the Bipolar SPWM Inverter", International Journal of Engineering and Innovative Technology (IJEIT) Volume 7, Issue 11, May 2018

S. R. Savanur and K. Teli, "Simulation and state space representation of single phase five level h-bridge inverter using MATLAB," 2018 International Conference on Recent Innovations in Electrical, Electronics \& Communication Engineering (ICRIEECE), Bhubaneswar, India, pp. 1832-1837, 2018,

C. R. Balamurugan, S. P. Natarajan*, R. Bensraj:"“Control Techniques For Various Bipolar PWM Strategies Of Three Phase Five Level Cascaded Inverter”, Journal of Engineering Science and TechnologyVol. 10, No. 7 pp. $878-897$ (2015)

T. Bhattacharjee, M. Jamil and A. Jana, "Design of SPWM based three phase inverter model," 2018 Technologies for Smart-City Energy Security and Power (ICSESP), Bhubaneswar, India, pp. 1-6, 2018,

K. Gupta, K. T. Chaturvedi, B. Singh, T. Sharma and J. Srikakolapu, "Simulation of a cascade connected Hbridge five level inverter," 2014 IEEE International Conference on MOOC, Innovation and Technology in Education (MITE), Patiala, India, pp. 165-170, 2014,

A. Palanisamy et al., "A New Three-Level Three-Phase Boost PWM Inverter for PV Applications," 2018 IEEE Energy Conversion Congress and Exposition (ECCE), Portland, OR, USA, pp. 7191-7196, 2018,

A Qazalbash, A Amin, A Manan, M Khalid, "design and implementation of microcontroller based PWM technique for sine wave inverter" International Conference on power Engineering Energy and Electrical Drives, , P 163-167, March 2009, IEEE.

A. Nabae, I. Takahashi and H. Akagi, "A New Neutral-Point-Clamped PWM Inverter", IEEE Transactions on Industry Applications, vol. 17, no. 5, pp. 518-523, 1981...

L Hassaine, E Olías, M Haddadi, A Malek, "Asymmetric SPWM used in inverter grid connected" Revue des Energies Renouvelables Vol. 10, pp. 421-429, 2007.

S. Kouro, M. Malinowski, K. Gopakumar, J. Pou, L. Franquelo, Wu Bin, et al., "Recent Advances and Industrial Applications of Multilevel Converters", IEEE Transactions on Industrial Electronics, vol. 57, no. 8, pp. 2553 2580, 2010..

B. Zhang, X. Du, J. Zhao, J. Zhou and X. Zou, "Impedance modeling and stability analysis of a three-phase three-level NPC inverter connected to the grid," in CSEE Journal of Power and Energy Systems, vol. 6, no. 2, pp. 270-278, June 2020,

Mohamed A.Ghalib, Yasser S.Abdalla, R. M.Mostafa, "Design and implementation of a Pure Sine Wave Single Phase Inverter for Photovoltaic Applications“" in American socoity for Engineering Education in 2014 